\title{
Present Day Regional Mass Loss of Greenland Observed with Satellite Gravimetry
}

\author{
E. Schrama $\cdot$ B. Wouters $・$ B. Vermeersen
}

Received: 21 September 2010/ Accepted: 28 January 2011/Published online: 15 March 2011

(C) The Author(s) 2011. This article is published with open access at Springerlink.com

\begin{abstract}
This paper summarizes results obtained for Greenland's mass balance observed with NASA's GRACE mission. We estimate a Greenland ice sheet mass loss at $-201 \pm 19 \mathrm{Gt} /$ year including a discernible acceleration of $-8 \pm 7 \mathrm{Gt} /$ year $^{2}$ between March 2003 and February 2010. The mass loss of glacier systems on the South East of Greenland has slowed down while the mass loss increases toward the North along the West side of Greenland. The mass balance can be compared with results obtained by a regional climate model of the Greenland system and ice sheet altimeter data obtained from NASA's ICEsat mission. Our GRACE-only results differ to within 15\% from these independently calculated values; we will comment on the possible causes and the quality of the glacial isostatic adjustment model which is used to correct geodetic datasets.
\end{abstract}

Keywords Temporal gravity · Greenland ice sheet $\cdot$ Satellite gravimetry

\section{Introduction}

The Gravity Recovery and Climate Experiment (GRACE) was launched in March 2002. It consists of two satellites separated by $\approx 220 \mathrm{~km}$ orbiting at $450-500 \mathrm{~km}$ above the Earth's surface, see also Tapley et al. (2004). In this paper we rely on GRACE derived monthly sets of spherical harmonic coefficients that describe the gravity field of the Earth. The temporal variations in such gravity fields relative to a long term average gravity field provide the capability to calculate monthly maps of surface water thickness which come with a spatial resolution of $\approx 300 \mathrm{~km}$.

With the help of the multi-basin estimation technique introduced in Wouters et al. (2008) we translate the observed water thickness variations into mass time series for 16

E. Schrama $(\bowtie) \cdot$ B. Vermeersen

Delft University of Technology, Kluyverweg 1, 2629 JA, Delft, The Netherlands

e-mail: e.j.o.schrama@tudelft.nl

B. Wouters

The Royal Netherlands Meteorological Institute, Wilhelminalaan 10,

3732 GK, De Bilt, The Netherlands 
basins defined within the Greenland system, see Fig. 1. There are four additional basins near Greenland (Ellesmere Island, Baffin Island, Iceland and Svalbard) where we also calculate mass time series. A sum of the estimated basin mass time signals yields a realistic estimate for the total mass change of the Greenland system. The motivation for writing this paper is to provide background information to a presentation with the same title at the workshop on the Earth's Cryosphere and Sea level Change held at the International Space Science Institute in Bern, Switzerland, March 22-27, 2010.

In Sect. 2 we show the results obtained with GRACE for Greenland's mass using a new implementation of the forward method discussed in Wouters et al. (2008), in Sect. 3.1 we compare the obtained solution with other solutions that only depend on GRACE, in Sect. 3.2 we compare our results to independent mass balances derived from satellite altimetry, in Sect. 3.3 we discuss a comparison with an independent mass balance calculation that does not depend on GRACE or satellite gravimetry, in Sect. 3.4 we discuss the possible consequences of a new glacial isostatic adjustment model that was recently published and in Sect. 4 we discuss the outlook for future research on Greenland's mass balance.

\section{Mass Loss Trend and Acceleration of the Greenland Ice Sheet}

The GRACE system described in Tapley et al. (2004) provides monthly estimates for the Earth's geoid up to a spatial resolution of approximately $300 \mathrm{~km}$ which is mostly governed by the height of the GRACE system above the Earth's surface. Under suitable conditions a sufficient number of GRACE measurements becomes available to compute degree and order 60 spherical harmonic coefficient sets at monthly intervals, whereby it should be remarked that the Centre Nationales de Etudes Spatiales (CNES) in Toulouse France produces GRACE gravity fields at 10 day intervals, cf. Bruinsma et al. (2010). Two standard GRACE spherical harmonic coeffient sets from the Center of Space Reseach at the University of Texas (CSR) and the Geo-Forschungs Zentrum in Potsdam (GFZ) are developed by the GRACE science team. These solutions can be downloaded from ftp://podaac.jpl.nasa.gov/grace/data/L2/.

The raw GRACE data consists of inter-satellite distance variations including GPS and accelerometer data collected on both spacecrafts. After processing this data we obtain a level-2 product that provides a monthly set of spherical harmonic coefficients that describe the gravity field of the Earth. During this process all high frequency mass variations that occur within the processing month are removed so that the produced monthly gravity fields are corrected for effects from ocean tides and atmospheric air pressure variations. The

Fig. 1 Basin definitions and index numbers within the Greenland system, including, in red, the 2,000 m contour; for elevations above $2,000 \mathrm{~m}$, the indices are increased by 8

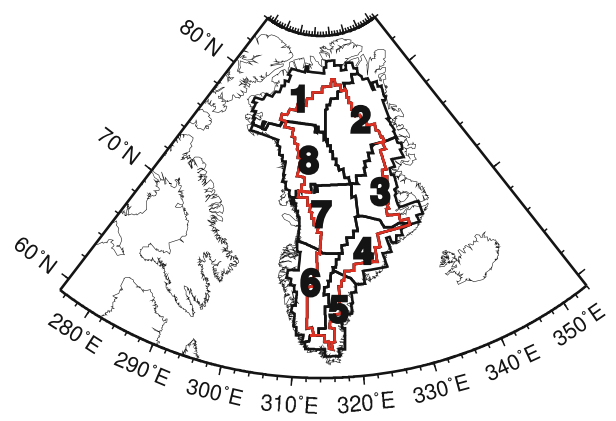


latter both affect the Earth's crust through atmospheric pressure loading, but also play a role in a barotropic ocean model which is used to correct the GRACE gravity fields.

After removal of the static part of the geoid and correction for the glacial isostatic adjustment of the Earth, for which we initially use the models of Paulson et al. (2007) and Peltier (2004), a residual monthly geoid can be obtained from the GRACE system. If we assume that the resulting geoid variations after the GIA correction occur as a result of mass variations on the Earth's surface, and if we assume that the GRACE system is able to observe the signal with an infinite spatial resolution then an elastic loading theory can be used to compute monthly equivalent water thickness $y_{t}(x)$ where $t$ is time and $x$ the geographic location, for details see Wouters (2010) and Schrama and Wouters (2011).

In reality the spatial resolution of GRACE is limited for a number of reasons: (1) GRACE samples the gravity field from an orbit that occasionally experiences resonances resulting in unfavorable repeating ground track patterns, (2) the altitude of the GRACE satellites is between 450 and $500 \mathrm{~km}$, and (3) the equivalent water thickness maps are convolved with an isotropic, homogeneous spherical Gaussian function $G$ which assists in de-striping these maps.

A separate discussion is the use of a filter technique based on an empirical orthogonal function (EOF) approximation of the GRACE level-2 data or the computed water thickness maps. In the paper of Wouters et al. (2008) the spherical harmonic coefficients are freed from noise by means of an EOF approximation and in Schrama and Wouters (2011) an EOF approximation is used to identify noisy months in the GRACE level-2 series.

In the following GRACE observed water thickness maps are represented as $z_{t}(x)=$ $G\left(y_{t}(x)\right)$ and the task is to use this information to derive mass variations within basins as shown in Fig. 1. For this reason the defocussing method considers the linear system:

$$
z_{t}(x)=\sum_{i=1}^{N} \alpha_{t i} \beta_{i}(x)+\epsilon_{t}(x)
$$

where $z$ is the convoluted water thickness observed by GRACE at month $t$ at geographic location $x$. We define $N$ basins in the model domain, the coefficients $\alpha_{t i}$ describe a uniform water thickness in basin $i$ at month $t$ and the functions $\beta_{i}(x)$ model the contribution of unit basin function $i$ which is defined by the basin shape and the selected Gaussian smoothing radius, for details see Schrama and Wouters (2011). Equation (1) is solved by minimization of a cost function $\epsilon_{t}(x)^{\prime} Q^{-1} \epsilon_{t}(x)$ where $Q$ is the covariance matrix of the GRACE water thickness observations. The solved for coefficients $\alpha_{t i}$ are converted into a mass change per basin which results in a time series for basin $i$.

A first finding with the method described above is that the choice of the number of basins greatly affects Greenland's mass loss trend function which can be demonstrated by representing the ice sheet by one or more basins. If the Greenland ice sheet is modeled by a single basin being the overlap over compartments 1-16 in Fig. 1 then the mass change $d M / d t$ becomes $-146 \pm 14 \mathrm{Gt} /$ year where the error margin follows from a $95 \%$ confidence interval. If we use basins 1-8 within the coastal zone then we get $-207 \pm 18 \mathrm{Gt} / \mathrm{year}$, when the system is fully described by all 16 basins as shown in Fig. 1 then we get $-219 \pm 19 \mathrm{Gt} / \mathrm{year}$. Finally, if we include the four surrounding regions Ellismere Island, Baffin Island, Iceland and Svalbard (the EBIS region) then we get $-250 \pm 28 \mathrm{Gt} /$ year. These mass change rates are computed with consideration of a 3 degree Gaussian smoothed radius. As input for the de-focussing method we used equivalent water thickness maps derived from monthly GRACE spherical harmonic coefficients provided by the CSR, the GFZ and the University of Bonn. GRACE data was used between March 2003 and Feb 
2010 and we applied the glacial isostatic adjustment models from Paulson et al. (2007) and Peltier (2004) to obtain mass loss rates.

The difference between modeling the Greenland ice sheet with 1 or 8 basins hints to an approximation error of the here described de-focusing method. This problem may be avoided by defining a sufficient number of basins.

From the above results we conclude that there is a difference of approximately $12 \mathrm{Gt} /$ year between a solution of 8 coastal basins and 16 Greenland basins, and a difference of approximately $31 \mathrm{Gt} /$ year between a full 16 basin Greenland System (GS) solution and a 20 basin solution that includes the EBIS area. Since there are noticeable correlations in the solution one can not rely on differencing methods because mass changes that occur by adding a few basins to the system will propagate between the involved basins.

For numerical reasons discussed in Schrama and Wouters (2011) we decided to merge the GS above 2,000 $\mathrm{m}$ into one basin and to allow for mild a priori constraints, i.e. greater than $10^{6} \mathrm{Gt}^{2}$ is assumed as a priori variance by modeled basin. This yields a 13-basin configuration where the mass change trend of the GS becomes $-201 \pm 19 \mathrm{Gt} /$ year, below $2,000 \mathrm{~m}$ we find $-250 \pm 20 \mathrm{Gt} /$ year, above $2000 \mathrm{~m}$ we see a mass gain of $49 \pm 10 \mathrm{Gt} /$ year, whereby we remark that the errors below and above $2,000 \mathrm{~m}$ are correlated by -0.89 . For the EBIS region we find $-51 \pm 17 \mathrm{Gt} /$ year and the correlation of errors to the rest of the solution is between -0.3 and 0.3 . The full system consisting of the GS and the EBIS region experiences a mass loss of $-252 \pm 28 \mathrm{Gt} /$ year and an acceleration of $-22 \pm 4 \mathrm{Gt} /$ year $^{2}$ where more than half of the acceleration signal comes from the EBIS region. All reported values are obtained between from GRACE data collected between March 2003 and February 2010.

The time series by basin in the 13-basin solutions do not only show a linear trend; there are also unique accelerations and annual signals for each basin. The mass change rates and accelerations within the coastal zone of Greenland are shown in Figs. 2 and 3, respectively, for March 2003-February 2010. Any trend or acceleration of the Greenland system as a whole is by definition an approximation because it is the sum of mass changes that originate mostly from the coastal zone of the GS.

Fig. 2 Mass loss rates in Gt/year in the Greenland system derived by the de-focussing method. The red zone of the color bar is for negative mass change rates

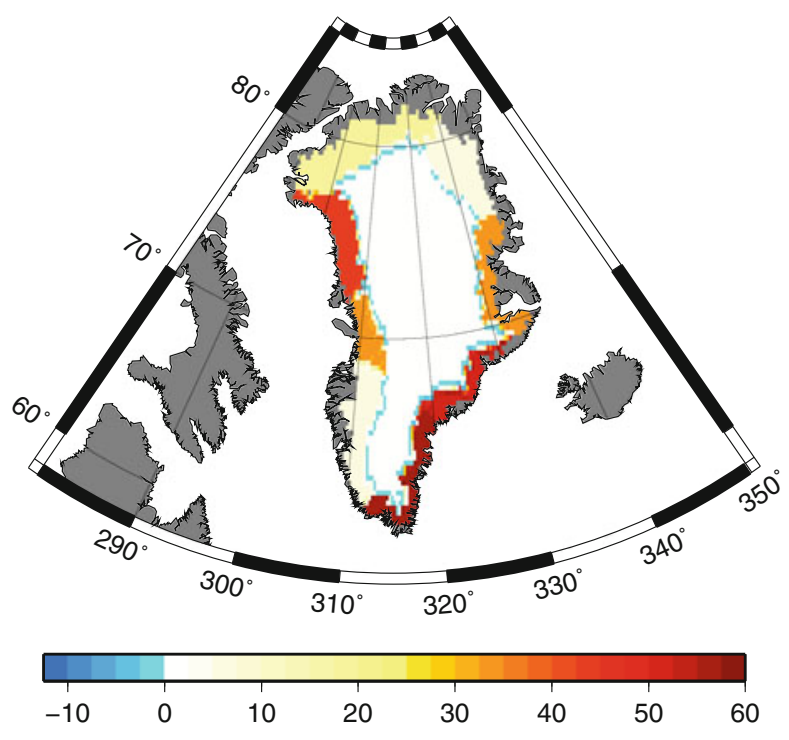


Fig. 3 Mass change accelerations in $\mathrm{Gt} / \mathrm{year}^{2}$ by compartment in the Greenland system. The red zone indicates that the mass change trends are becoming more negative
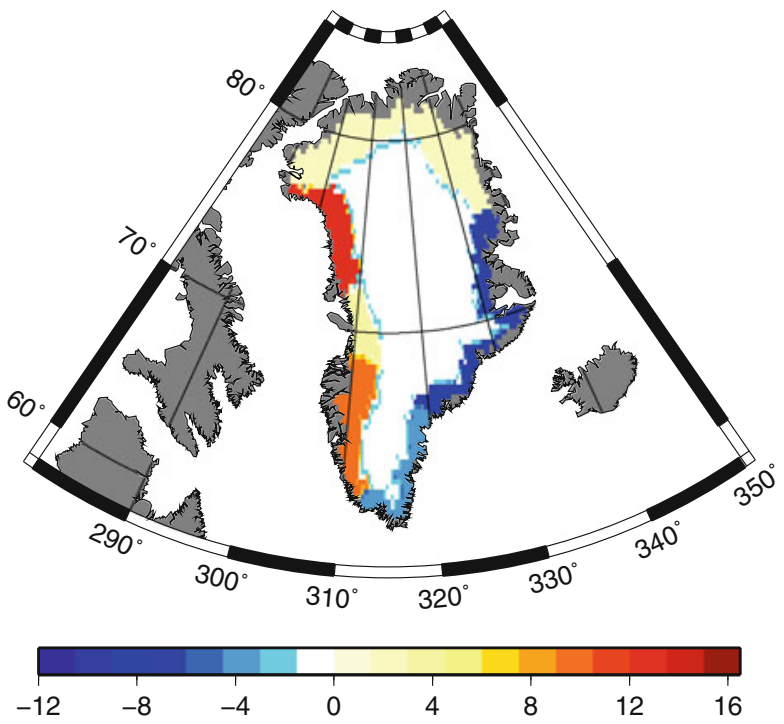

\section{Discussion}

In this section we will compare our obtained solution for the 13-basin configuration to existing GRACE-only mass balance estimates (MBE), altimeter derived MBEs, and climatologic MBEs of the Greenland ice sheet. Due to the recent developements in the Glacial Isostatic Adjustment (GIA) community we will also comment on Wu et al. (2010) who suggested that it may be necessary to develop a new GIA model for Greenland.

\subsection{Comparison to "GRACE-Only" Solutions}

When we compare our results to published mass balance estimates of Greenland we notice that Velicogna (2009) finds - $137 \mathrm{Gt} /$ year between 2002-2003 to $-286 \mathrm{Gt} / \mathrm{year}$ in 2007-2009. Their suggestion is that one could interpret this result as a mass loss rate of $-230 \pm 33 \mathrm{Gt} /$ year and an acceleration of $-30 \pm 11 \mathrm{Gt} /$ year $^{2}$. In Wouters et al. (2008) we reported a mass change rate of $-179 \pm 25 \mathrm{Gt} /$ year for the time period 2003-2008; the solution of Wouters et al. (2008) is compatible with the solution presented here because of the acceleration effect. For a 13-basin solution we find with the method described in Sect. 2 and with consideration of the gravity field solution provided by the CSR, the GFZ and the university of Bonn, including the GIA models of Paulson et al. (2007) and Peltier (2004), an acceleration of $-8 \pm 7 \mathrm{Gt} / \mathrm{year}^{2}$ for the GS, and for the combination of the GS and the EBIS we get $-22 \pm 4 \mathrm{Gt} /$ year $^{2}$.

A Greenland mass loss rate difference is observed between the methods of Wouters et al. (2008) and Velicogna (2009) because of the contribution of the EBIS region. The averaging kernel method used by Velicogna (2009) partly overlaps the neighborhood of Greenland so that this method is affected by mass loss processes in adjacent regions as explained in Wouters et al. (2008) and Wouters (2010).

Whereas both methods are based on monthly GRACE spherical harmonic coefficients provided by the Center of Space Research (CSR) at Austin the results of Luthcke et al. (2010) depend on their implementation of a mass concentration model (mascon model) as 
reported in Luthcke et al. (2006) and Rowlands et al. (2005). At the European Geosciences Union meeting held in Vienna, Luthcke et al. (2010) showed that their Greenland mass loss rate stands at $-177 \pm 6$ Gt/year during August 2003-August 2009. This mascon solution displays a large signal in the coastal zone of $-242 \pm 19 \mathrm{Gt} /$ year while above 2,000 $\mathrm{m}$ a mass gain of $65 \pm 9 \mathrm{Gt} /$ year is observed; furthermore there is no evidence for an acceleration in the Goddard Space Flight Center (GSFC) mascon solution. In Schrama and Wouters (2011) it is reported that a significant anti-correlation occurs between the total mass variation in coastal zone and the area above 2,000 $\mathrm{m}$ on Greenland and that the separation of both signals obtained by the de-focussing method is difficult. Nevertheless for an unconstrained 13 basin solution we also find a mass gain of $49 \pm 10 \mathrm{Gt} /$ year over $2,000 \mathrm{~m}$ in the GS.

\subsection{Comparison to Solutions from Satellite Altimetry}

Any satellite altimetry mass balance estimate comes with the fundamental problem that it provides a volume estimate and that firn compaction affects the quality of the computed mass effects by basin. A second effect is that mass loss on Greenland occurs in the coastal margins where all altimeter systems face data interpretation problems because of a rugged topography. The MBE from radar altimetry is discussed in Zwally et al. (2005) for the period 1992-2002 with ERS-1 and ERS-2 data. Their conclusion is that the coastal margin of Greenland was losing $-42 \pm 2 \mathrm{Gt} /$ year below the equilibrium line but that Greenland was gaining mass by a rate of $+53 \pm 2 \mathrm{Gt} /$ year inland. ICEsat provides estimates of the topographic change measured by a laser as is discussed in for instance Pritchard et al. (2009) who find thinning along the coastal margin and thickening above 2,000 $\mathrm{m}$ on Greenland. A recent Greenland MBE derived from ICEsat altimetry data is $-171 \pm 4 \mathrm{Gt} /$ year during 2003-2007 as explained in Zwally et al. (2011), while Sørensen et al. (2010) mention $-210 \pm 21 \mathrm{Gt} /$ year for October 2003-March 2008. In Zwally et al. (2011) the rate of mass gain above 2,000 $\mathrm{m}$ is compared between 1992-2002 and 2003-2007. Their conclusion is that the mass change in this area decreased from 44 to $28 \mathrm{Gt} / \mathrm{year}$, while below $2,000 \mathrm{~m}$ the mass change increased from -51 to $-198 \mathrm{Gt} / \mathrm{year}$.

\subsection{Comparison to Climatologic Mass Balance}

The Greenland mass balance may also be obtained from regional climate models such as Regional Climate model for Greenland maintained by Michiel van den Broeke (RACMO/ GL) which are an essential contribution in modeling the surface mass balance (SMB). In van den Broeke et al. (2009) the SMB follows from precipitation, evaporation and seepage of meltwater; another required component is the glacier discharge (D) which is measured with the help of satellite interferometry as is explained in Rignot and Kanagaratnam (2006). The mass balance for Greenland that should be compared to the values obtained from GRACE, ICEsat and ERS-1 and 2 is the difference SMB-D. This calculation results in $-237 \pm$ $20 \mathrm{Gt} /$ year for the Greenland ice sheet according to van den Broeke et al. (2009). Their estimate is entirely independent of any assumption about the gravity field of the Earth including corrections to the gravity fields as a result of glacial isostatic adjustment of the Earth which must be applied to the monthly GRACE gravity fields to derive a surface mass balance.

The Greenland mass change rate reported in van den Broeke et al. (2009) is within 15 percent of the result obtained by Wouters et al. (2008), Velicogna (2009), Schrama and Wouters (2011), and Sørensen et al. (2010). Although the time window is nearly compatible it is not well understood why the results obtained by Luthcke et al. (2010) and 
Table 1 Published mass balance estimates (MBEs) for Greenland based on various methods

\begin{tabular}{llllll}
\hline Authors & MBE & Coastal & Inland & Period & Method \\
\hline Zwally et al. (2005) & $+11 \pm 3$ & $-42 \pm 2$ & $53 \pm 2$ & $92-02$ & ERS-1/2 \\
Zwally et al. (2011) & $-171 \pm 4$ & -198 & 28 & $03-07$ & ICEsat \\
Luthcke et al. (2010) & $-177 \pm 6$ & $-242 \pm 19$ & $65 \pm 9$ & $03-09$ & GRACE \\
Wouters et al. (2008) & $-179 \pm 25$ & $-186 \pm 19$ & $7 \pm 18$ & $03-07$ & GRACE \\
Schrama and Wouters (2011) & $-201 \pm 19$ & $-250 \pm 20$ & $49 \pm 10$ & $03-09$ & GRACE \\
Sørensen et al. (2010) & $-210 \pm 21$ & & & $03-08$ & ICEsat \\
Velicogna (2009) & $-230 \pm 33$ & & & $02-09$ & GRACE \\
van den Broeke et al. (2009) & $-237 \pm 20$ & & & $03-08$ & SMB-D \\
\hline
\end{tabular}

Zwally et al. (2011) deviate from the MBE published by van den Broeke et al. (2009) by more then the allowed confidence interval even if one would correct for known accelerations of the Greenland ice sheet, see also Table 1.

\subsection{Consequences of a New Post Glacial Rebound Model}

For the calculation of the Greenland ice sheet mass change trend and accelerations with the 13-basin approximation reported in Sect. 3.1 we tested two implementations of GIA models for Greenland, namely that of Peltier (2004) and Paulson et al. (2007). Both models are based on the same ice history model ICE-5G that originates from Peltier (2004). The GIA model of Paulson et al. (2007) is obtained by adjusting the viscosity structure within the Earth's crust to find a best match to the GRACE data. The conclusions with both used GIA models is that there are no significant differences in the obtained Greenland mass loss changes which was the status quo during the workshop in March 2010. Since the workshop $\mathrm{Wu}$ et al. (2010) suggested that a new GIA model should be constrained by a larger contribution to mass variations in Greenland.

In Wu et al. (2010) the authors use deformation vectors estimated from GPS data acquired from stations on the Greenland coast, including ocean bottom pressure predictions acquired from a data assimilation model and the CSR level-2 RL04 GRACE data from April 2002 to December 2008. One of the possibilities might be that the ICE-5G(VM2) model in Peltier (2004) underestimates GIA in the Greenland system. This was the a priori model that went into the simulations and the data-assimilation technique hinting at a $-0.56 \mathrm{~mm}$ per year GIA geoid trend rather than the $+0.1 \mathrm{~mm}$ per year trend that is associated with the ICE$5 \mathrm{G}(\mathrm{VM} 2)$ model. But uncertainties in Late-Pleistocene deglaciation is only one of the possibilities; another one is Late-Holocene glaciation. In Wu et al. (2010) the possibility is mentioned of more recent additional net past ice accumulation of about 100-300 m. The Earth starts to deform viscously typically on time scales of a few 100 years, so that additional recent ice mass accumulation between 6,000 years ago and the present might induce additional present-day crustal subsidence, cf. Sparrebom et al. (2006).

The conclusions of Wu et al. (2010) are that the Greenland Ice Sheet would experience about half of the present day mass loss, i.e. they find $-104 \pm 23 \mathrm{Gt} /$ year between 2002 and 2008, which was later corrected to $-130 \mathrm{Gt} /$ year (X. Wu, personal communication). The consequence of the results in Wu et al. (2010) is that the difference widens between GRACE-based Greenland mass loss rates and the MBE obtained by climatologic studies, see Sect. 3.3 Also, the difference between altimeter derived MBEs and the climatologic studies would increase when an alternative GIA correction as suggested in Wu et al. (2010) 
is used for correcting altimeter data. Whether the approach of Wu et al. (2010) should be adopted is a challenge for further studies, since the GIA correction is fundamental to all discussed gravimetry and altimeter methods shown in Table 1 except for the climatologic MBE as reported by van den Broeke et al. (2009).

\section{Outlook}

With the help of a de-focussing method reported in Sect. 3.1 applied to a 13-basin solution we find a Greenland system mass loss rate and acceleration that is consistent with the results published by Velicogna (2009), van den Broeke et al. (2009) and altimeter derived MBEs from Zwally et al. (2011) and Sørensen et al. (2010). As a result our Greenland mass balance estimates from GRACE agree to within 15\% with independent mass balances derived from climatological studies and ICEsat altimetry studies.

The physical significance of an acceleration term as presently observed within the Greenland system is not well understood. The mass loss rate in Fig. 2 is for instance not uniform along the shore, neither is the acceleration of mass change as shown in Fig. 3. The glaciers along the South East of Greenland are still losing mass, but the acceleration map shows that this process is slowing down, whereas the basins on the West and North West of Greenland have increased their rate of mass loss. The GRACE derived regional climatologies within the coastal basins do resemble the results obtained by van den Broeke et al. (2009). Yet more research is necessary to refine the conclusions, and in particular the long term behaviour of the mass change on Greenland including its relation to known circulation pattern changes in the ocean and atmosphere related, e.g., to the North Atlantic oscillation and the El Niño Southern Oscillation.

The new GIA correction by Wu et al. (2010) provides a new direction in post glacial rebound research. The method uses GPS deformation vectors near Greenland, GRACE data, and an ocean model yielding ocean bottom pressure data. At the same time the GIA model developed by $\mathrm{Wu}$ et al. (2010) considerably widens the gap between the Greenland mass balance results of van den Broeke et al. (2009) and the GRACE mass loss estimates discussed in Velicogna (2009), Wouters et al. (2008), Schrama and Wouters (2011) and Luthcke et al. (2010). Whether the Greenland GIA model has converged may depend on further research focussing on the interpretation of geologic sea level records along the Greenland shore, such as discussed in Sparrebom et al. (2006).

Acknowledgments Bert Wouters was funded by the Netherlands Organisation for Scientific Research NWO; Paulo Stocchi at the Delft University of Technology provided helpful suggestions related to the role of the glacial isostatic adjustment in connection with GRACE.

Open Access This article is distributed under the terms of the Creative Commons Attribution Noncommercial License which permits any noncommercial use, distribution, and reproduction in any medium, provided the original author(s) and source are credited.

\section{References}

Bruinsma S, Lemoine J-M, Biancale R, Valès N (2010) CNES/GRGS 10-day gravity field models (release 2) and their evaluation. Adv Space Res 45:587-601

Luthcke SB, Zwally HJ, Abdalati W, Rowlands DD, Ray RD, Nerem RS, Lemoine FG, McCarthy JJ, Chinn DS (2006) Recent Greenland ice mass loss by drainage system from satellite gravity observations. Sci Agric 314:1286-1289. doi:10.1126/Science.1130776 
Luthcke SB, McCarthy JJ, Rowlands DD, Arendt A, Sabaka T, Boy JP, Lemoine FG (2010) Observing changes in the land ice from GRACE and future spaceborne multi-beam laser altimeters. EGU conference paper EGU2010-5576, Vienna, Austria

Paulson A, Zhong S, Wahr J (2007) Inference of mantle viscosity from GRACE and relative sea level data. Geophys J Int 171:497-508. doi:10.1111/j.1365-246X.2007.03556.x

Peltier WR (2004) Global glacial isostasy and the surface of the ice-age Earth: the ICE-5G (VM2) model and GRACE. Ann Rev Earth Planet Sci 32:111-149

Pritchard Hamish D, Arthern Robert J, Vaughan David G, Edwards Laura A (2009) Extensive dynamic thinning on the margins of the Greenland and Antarctic ice sheets. Nat Biotechnol 461:971-975. doi: 10.1038/nature08471

Rignot E, Kanagaratnam P (2006) Changes in the velocity structure of the Greenland ice sheet. Science 311, 17 Feb 2006. doi:10.1126/science.1121381 (2006)

Rowlands DD, Luthcke SB, Klosko SM, Lemoine FGR, Chinn DS, McCarthy JJ, Cox CM, Anderson OB (2005) Resolving mass flux at high spatial and temporal resolution using GRACE intersatellite measurements. Geophys Res Lett 32:L04310. doi:10.1029/2004GL021908

Schrama EJO, Wouters B (2011) Revisiting Greenland ice sheet mass loss observed by GRACE, to appear in J Geophys Res 116. doi:10.1029/2009JB006847

Sørensen LS, Simonsen SB, Nielsen K, Lucas-Picher P, Spada G, Adalgeirsdottir G, Forsberg R, Hvidberg CS (2010) Mass balance of the Greenland ice sheet a study of ICESat data, surface density and firn compaction modelling. Cryosphere Discuss 4:2103-2141. doi:10.5194/tcd-4-2103-2010

Sparrenbom CJ, Bennike O, Björck S, Lambeck K (2006) Relative sea-level changes since 15,000 cal. year BP in the Nanortalik area, southern Greenland. J Quatern Sci 21(1):29-48. doi:10.1002/jqs.940

Tapley BD, Bettadpur S, Watkins M, Reigber C (2004) The gravity recovery and climate experiment: mission overview and early results. Geophys Res Lett 31:L09607. doi:10.1029/2004GL019920

van den Broeke M, Bamber J, Ettema J, Rignot E, Schrama E, Jan van de Berg W, van Meijgaard E, Velicogna I, Wouters B (2009) Partitioning of Greenland mass loss. Sci Agric 326:984-986. doi: $10.1126 /$ science. 1178176

Velicogna I (2009) Increasing rates of ice mass loss from the Greenland and Antarctic ice sheets revealed by GRACE. Geophys Res Lett 36:L19503. doi:10.1029/2009GL040222

Wu X, Heflin MB, Schotman H, Vermeersen BLA, Dong D, Gross RS, Ivins ER, Moore AW, Owen SE (2010) Simultaneous estimation of global present-day water transport and glacial isostatic adjustment. Nat Geosci. Published online: 15-Aug-2010. doi:10.1038/NGEO938

Wouters B, Chambers D, Schrama EJO (2008) GRACE observes small-scale mass loss in Greenland. Geophys Res Lett 35:L20501. doi:10.1029/2008GL034816

Wouters B (2010) Identification and modelling of Sea level change contributors, on GRACE satellite gravity data and their application to climate monitoring, PhD. Thesis, Delft University of Technology, The Netherlands, http://www.ncg.knaw.nl/Publicaties/Geodesy/73Wouters.html

Zwally HJ, Giovinetto MB, Li J, Cornejo HG, Beckley MA, Brenner AC, Saba JL, Yi D (2005) Mass changes of the Greenland and Antarctic ice sheets and shelves and contributions to sea-level rise: 19922002. J Glaciol 51(175)

Zwally Jay H, Li J, Brenner AC, Beckley M, Cornejo HG, DiMarzio J, Giovinetto MB, Neumann TA, Robbins J, Saba JL, Yi D, Wang W (2011) Greenland ice sheet mass balance: distribution of increased mass loss with climate warming; 200307 versus 19922002. J Glaciol 57(201) 